\title{
Synchronous acute appendicitis and acute cholecystitis, is it a myth or reality? A literature review
}

This article was published in the following Dove Press journal:

Open Access Emergency Medicine

\author{
Fatemah Buhamed' \\ Maged Edward ${ }^{2}$ \\ Abdullah Shuaib ${ }^{2}$ \\ 'Department of General Surgery, \\ Mubarak Al-kabeer Hospital, Kuwait, \\ Kuwait; ' ${ }^{2}$ Department of General Surgery, \\ Mubarak Al-kabeer Hospital, Kuwait, \\ Kuwait
}

\begin{abstract}
Acute appendicitis and acute cholecystitis are some of the most common surgical emergencies in the emergency department. Both conditions are common causes of abdominal pain. We had a discussion about co-existing acute appendicitis and cholecystitis and if it is a myth. The concurrent presentation of acute appendicitis and cholecystitis is thought to be rare. A PubMed search of MEDLINE was performed using a combination of the keywords "acute appendicitis" and "acute cholecystitis" to obtain case reports. The search returned 11 case reports of co-existent acute appendicitis and acute cholecystitis. The aim of this review is to broaden the prospective of emergency physicians to consider more than one pathology as the cause of abdominal pain. The concurrent presentation of acute appendicitis and cholecystitis is rare but should be considered to avoid complications such as perforation and septicemia.
\end{abstract}

Keywords: synchronous, acute appendicitis, acute cholecystitis

\section{Introduction}

Acute appendicitis and acute cholecystitis are some of the most common surgical emergencies in the emergency department. ${ }^{1,2}$ and both are common causes of abdominal pain. ${ }^{3}$ Acute cholecystitis requiring surgery is frequent in developed countries and increases with age. ${ }^{4}$ We discussed in our surgical department the possibility of co-existing appendicitis and cholecystitis and if it was a myth or reality. Numerous studies reported that they occur simultaneously. ${ }^{1,3-8}$ We reviewed the literature for case reports of co-existing appendicitis and cholecystitis.

\section{Methods}

A PubMed search of MEDLINE was performed to identity case reports, using a combination of the keywords "acute appendicitis" and "acute cholecystitis". The search was not limited by language, publication year or origin. All case reports without full text reports or abstracts were excluded from the search. The search returned 11 case reports of co-existent acute appendicitis and acute cholecystitis. The search was conducted in January 2018 and June 2018. The cases were compared to each other using Microsoft Excel.

\section{Results}

The 11 case reports referred to seven female and four male patients. The average age of the patients was 52.3 years. The initial presentation in four cases was upper abdominal pain. ${ }^{1,7,9,10}$ Five cases presented with right-sided abdominal pain, ${ }^{3,4,6,9,11}$ and two cases
Department of General Surgery, Mubarak Al-kabeer Hospital, Shamiya, Block 7 , Street 72, House 10, Kuwait I30II, Kuwait

Email Shuaib.abdullah.77@gmail.com 
presented with diffuse or central pain. ${ }^{5,8}$ Six patients were diagnosed with synchronous acute appendicitis and cholecystitis by computed tomography (CT) ${ }^{1,3,5,6,8,11}$ Three cases were diagnosed with acute cholecystitis initially with abdominal ultrasound (US). ${ }^{4,7,10}$ All the patients underwent a surgical intervention, except one case that was managed with US-guided percutaneous gallbladder drainage and intravenous antibiotics. ${ }^{8}$ The cases are summarized in Table 1.

\section{Discussion}

Acute appendicitis and acute cholecystitis are common acute conditions in the emergency department. ${ }^{2}$ The establishment of the diagnosis of acute appendicitis can be a challenge, as $20-30 \%$ of patients present with atypical symptoms. ${ }^{12}$ Acute appendicitis can present with central diffuse pain in elderly patients, who also have a higher threshold of pain. ${ }^{5}$ Usually history of short right upper abdominal pain and murphy's sign in clinical examination for acute cholecystitis are less accurate in elderly patients. ${ }^{5}$ In the literature, there are some case reports of the concurrent presentation of acute appendicitis and cholecystitis. ${ }^{1,3-11}$ Acute cholecystitis can present as acalculous ${ }^{1,3,7}$ or calculous. ${ }^{4-6,8-11}$ The most frequent diagnostic modality reported in the 11 case reports was a CT scan of the abdomen. ${ }^{1,3,5}$ The accuracy of $\mathrm{CT}$ in diagnosing acute appendicitis was over $90 \% .{ }^{13}$ In general, CT scan is superior to clinical examination. ${ }^{5}$ There was no anatomical abnormality or relation mentioned in the reviewed case reports. ${ }^{1,3-11}$ The majority of patients with abdominal pain have single pathology, none the less double pathologies should be considered. ${ }^{6}$

Carter $^{14}$ described biliary reflux or gallbladder dyskinesia associated with acute appendicitis that was relieved after an appendectomy. According to one hypothesis of the pathogenesis of concurrent appendicitis and cholecystitis, it is the result of direct bacterial invasion or translocation from the muscularis propria of a gangrenous appendix into the portal venous system. ${ }^{5}$ The latter can lead to impairment of bile salt excretion and bacterial contamination of the gallbladder bile, causing acute cholecystitis. ${ }^{5}$ This hypothesis is supported by the incidence of hyperbilirumnia in acute appendicitis. ${ }^{15}$ Escherichia coli is the most frequent organism found in a perforated appendix, and $E$. coli endotoxin may lead to bile salt excretion and direct damage to liver cells at a cholangiolar level. ${ }^{16}$

Laparoscopy is considered the ideal single surgical modality to perform a cholecystectomy and an appendectomy in the same setting. ${ }^{7}$ However, some cases have been managed with open surgical procedures (open cholecystectomy, open

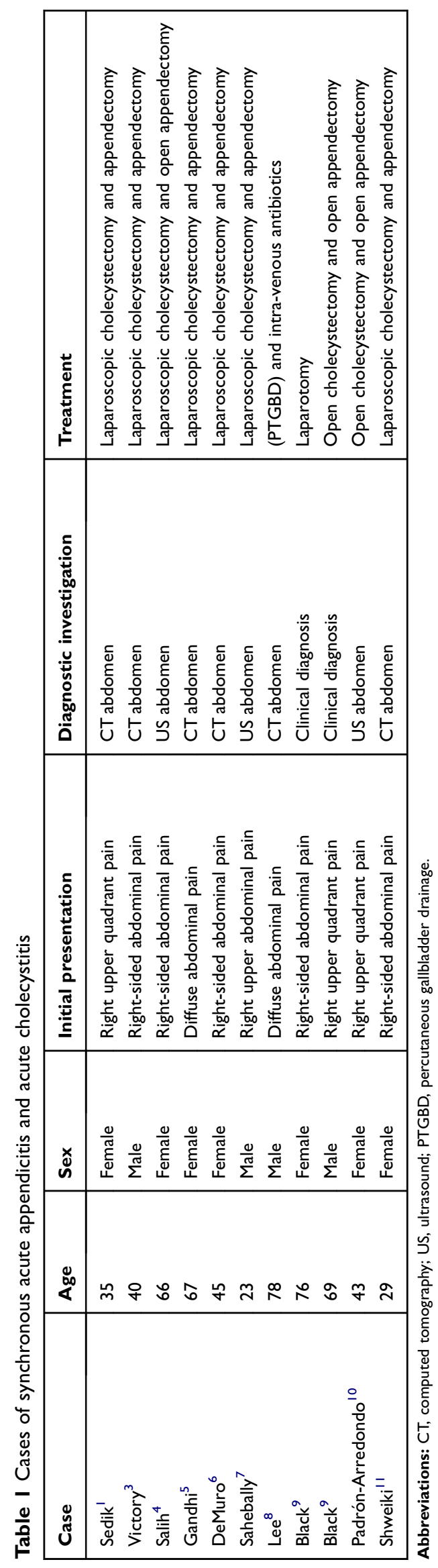


appendectomy and laparotomy $)^{9,10}$ or non-surgical treatment. ${ }^{8}$ To remove the gallbladder and appendix in the same setting, the placement of five ports, including a supraumbilical optical port is proposed. ${ }^{6}$

\section{Conclusion}

Abdominal pain in the emergency department is usually the result of a single pathology. Emergency physicians should consider more than one abdominal pathology as the cause of abdominal pain. The concurrent presentation of acute appendicitis and cholecystitis is rare but should be considered in investigations of abdominal pain to avoid complications such as perforation and septicemia.

\section{Disclosure}

The authors declare that there are no conflicts of interest regarding the publication of this paper.

\section{References}

1. Sedik A, Makhdoomi M, El Dakak A, El Houshy S. Simultaneous acute acalculous cholecystitis and acute appendicitis: a case report and literature review. Saudi Surg J. 2018;6(1):22.

2. Ferris M, Ghosh S. The global incidence of appendicitis: a systemic review of population based studies. Ann Surg. 2017;266(2):237-241.

3. Victory J, Meytes V, Parizh D, Ferzli G, Nemr R. Co-existent appendicitis and cholecystitis. Ann Laparosc Endosc Surg. 2017;2:54.

4. Salih AM, Kakamad FH, Abbas MH. Report peer reviewed | OPEN acute cholecystitis with perforated appendicitis : the first reported case. $J$ Case Rep Images Surg. 2016;2(April):57-59.
5. Gandhi J, Tan J. Concurrent presentation of appendicitis and acute cholecystitis: diagnosis of rare occurrence. BMJ Case Rep. 2015;2015:bcr2014208916.

6. DeMuro JP. Simultaneous acute cholecystitis and acute appendicitis treated by a single laparoscopic operation. Case Rep Surg. 2012;1-2:2012.

7. Sahebally SM, Burke JP, Nolan N, Latif A. Synchronous presentation of acute acalculous cholecystitis and appendicitis: a case report. $J$ Med Case Rep. 2011;5(1):551.

8. Lee T-Y, Chang HM, Shih ML, et al. Successful nonsurgical treatment for synchronous acute cholecystitis and acute appendicitis: a case report and review of the literatures. J Med Sci. 2014;34(3):121.

9. Black RB. Double pathology in acute cholecystitis. Aust N Z J Surg. 1977;47(6):798-801.

10. Padrón-Arredondo G, de Atocha Rosado-Montero M. [Synchronous acute cholecystolithiasis and perforated acute appendicitis. Case report]. Cir Cir. 2015;84(1):50-53.

11. Shweiki E, Price TP, Patel PH, et al. Synchronous acute appendicitis and acute cholecystitis: a discussion of a century's worth of epidemiologic, basic science, and clinical research, explicating the pathophysiology of a likely underrecognized historical condition. Am Surg. 2016;82(11):1140-1142.

12. Hamza Shirah B, Assad Shirah H, Awad Alhaidari W. Perforated appendix -delay in presentation rather than delay in the surgical intervention: retrospective database analysis of 2573 Saudi Arabian patients in 10 years. Int J Sci Study. 2016;4(1):32-36.

13. See TC, Watson CJE, Arends MJ, Ng CS. Atypical appendicitis: the impact of CT and its management. J Med Imaging Radiat Oncol. 2008;52(2):140-147. doi:10.1111/j.1440-1673.2008.01932.x

14. CARTER RF, HOTZ R. Reflex biliary dyskinesia relieved by appendectomY. J Am Med Assoc. 1939;113(5):399. doi:10.1001/ jama.1939.02800300029008

15. Estrada JJ, Petrosyan M, Barnhart J, et al. Hyperbilirubinemia in appendicitis: a new predictor of perforation. $J$ Gastrointest Surg. 2007;11(6):714-718. doi:10.1007/s11605-007-0156-5

16. Utili R, Abernathy CO, Zimmerman HJ. Endotoxin effects on the liver. Life Sci. 1977;20(4):553-568. doi:10.1016/0024-3205(77) 90458-1
Open Access Emergency Medicine

\section{Publish your work in this journal}

The Open Access Emergency Medicine is an international, peerreviewed, open access journal publishing original research, reports, editorials, reviews and commentaries on all aspects of emergency medicine. The manuscript management system is completely online and includes a very quick and fair peer-review system, which is all easy to use. Visit http://www.dovepress.com/testimonials.php to read real quotes from published authors. 